\title{
Prevalence of diabetes mellitus and impaired glucose tolerance in a rural community of Angola
}

\author{
Antonio D Evaristo-Neto, Maria Cristina Foss-Freitas, Milton C Foss
}

\begin{abstract}
Background: To determine the prevalence of diabetes mellitus (DM) and impaired glucose tolerance (IGT) in a rural community (Bengo) of Angola.

Methods: A random sample of 421 subjects aged 30 to 69 years (30\% men and $70 \%$ women) was selected from three villages of Bengo province. This cross-sectional home survey was conducted using a sampling design of stage conglomerates. First, clinical and anthropometric data were obtained and fasting capillary glucose level was determined. Subjects who screened positive (fasting capillary glucose $\geq 100 \mathrm{mg} / \mathrm{dl}$ and $<200 \mathrm{mg} / \mathrm{dl}$ ) and each sixth consecutive subject who screened negative (fasting capillary glucose $<100 \mathrm{mg} / \mathrm{dl}$ ) were submitted to the second phase of survey, consisting of the 75-g oral glucose tolerance test. Data was analyzed by the use of SAS statistical software.
\end{abstract}

Results: The prevalence rates of diabetes mellitus and IGT were $2.8 \%$ and $8.1 \%$, respectively. The age group with the highest prevalence of diabetes was 60 to 69 years (42\%). Impaired glucose tolerance prevalence was 38\% in the 40 to 49 year age group and it increased with age, considering that the 50 to 59 and 60 to 69 year age groups as a whole represent $50 \%$ of all subjects with impaired glucose tolerance. The prevalence of diabetes mellitus did not differ significantly between men (3.2\%) and women (2.7\%) $(p=0.47)$. On the other hand, the prevalence of impaired glucose tolerance among women showed almost twice that found in men $(9.1 \%$ vs. 5.6\%, respectively). Overweight was present in $66.7 \%$ of the individuals with diabetes mellitus and $26.5 \%$ of individuals with impaired glucose tolerance showed overweight or obesity.

Conclusions: Although the prevalence of diabetes mellitus was low, the prevalence of impaired glucose tolerance is considered to be within an intermediary range, suggesting a future increase in the frequency of diabetes in this population.

\section{Background}

Over the past century, diabetes mellitus was considered to be a rare medical condition in Africa. However, epidemiological studies carried out in the 90's have provided evidence of a different picture [1,2]. The prevalence of type 2 diabetes is high among Africans Americans, Afro-caribbeans and among African migrants in Europe, all of them sharing genetic ancestry with black Africans [3-5]. Diabetes and its long-term complications are higher in populations of African origin who have migrated to Western countries compared to Caucasians living in the same countries. Also, because of the adoption of Western lifestyles there is a global

\footnotetext{
* Correspondence: mcfoss@fmrp.usp.br

Department of Internal Medicine, Endocrinology and Metabolism Division, Ribeirào Preto School of Medicine, Sào Paulo University, Brazil
}

trend towards an increased incidence and prevalence of diabetes mellitus in Africa [2,6,7]. Indeed, Africa is experiencing one of the most rapid demographic and epidemiological transitions of the world history, characterized by a rise in the burden of non-communicable diseases. A prospective approach to the burden and prevention strategies has been hindered by the scarcity of data on diabetes in Africa [2,8]. The number of people with diabetes is increasing due to population growth, aging, urbanization, and increasing prevalence of obesity and physical inactivity [9]. Epidemiological studies of non-communicable diseases are rare in Africa and there is a need for more information on the prevalence of these diseases in this region of the world [2]. Quantifying the prevalence of diabetes and the number of people

\section{C) Biomed Central}


affected with diabetes is important for rational planning and adequate allocation of resources $[9,10]$.

The main objective of this population-based study was to determine the prevalence of diabetes mellitus and impaired glucose tolerance in a rural community (Bengo) of Angola. It was also analyzed the associations of glucose metabolism disturbances with body adiposity and/or hypertension.

\section{Methods}

A cross-sectional study was conducted in Caxito municipality, a training community of the Public Health Department of Agostinho Neto University School of Medicine. Caxito, the capital of Bengo province, is located $60 \mathrm{~km}$ north of Luanda, the capital of Angola. Its estimated population is of 54,592 with $54 \%$ of women and a predominant Bantu ethnic group. Caxito is divided in 15 villages with rural characteristics. The study was approved by the Scientific Council of Agostinho Neto University School of Medicine. Four medical students were trained as interviewers. Administrative authorities of Caxito municipality were informed and approved the study. Village populations were informed and invited to participate through meetings and advertisements via local radio broadcasting.

The minimum sample size of 400 people was calculated by estimating a possible prevalence of diabetes of $0.7 \%$, with an acceptable 95\% CI and 1\% maximum error. Sampling was undertaken using the conglomerate stage [11]. We randomly selected three rural villages. A two-stage survey was carried out. First, men and non-pregnant women aged 30 to 69 years were invited to participate in the study. After informed written consent was obtained, selected participants were asked to fast overnight. On the next day, a standard questionnaire was applied for identification data, and to collect anthropometric and clinical data. The subjects were then submitted to medical examination including the measurement of arterial blood pressure (BP) and anthropometric (weight, height, BMI = W $\left.(\mathrm{kg}) / \mathrm{H}^{2}(\mathrm{~m})\right)$ data. Capillary blood from a finger puncture was immediately analyzed for fasting blood glucose concentration by glucose oxidase method using an portable electronic blood glucose monitor (Accu Chek Advantage $^{\circledast}$ ) with commercially available strips (Dextrotix ${ }^{\oplus}$ ).

Individuals with fasting capillary glycemia (FCG) $\geq 100$ $\mathrm{mg} / \mathrm{dl}$ and $<200 \mathrm{mg} / \mathrm{dl}$ (positive screening test) were immediately submitted to a $75 \mathrm{~g}$ oral glucose tolerance test and capillary glucose was measured 2 hours later (second phase of the study). Every sixth consecutive individual who screened negative (FCG $<100 \mathrm{mg} / \mathrm{dl}$ ) was also submitted to the glucose load test. Previouslydiagnosed individuals and those with fasting or twohour capillary glycemia $\geq 200 \mathrm{mg} / \mathrm{dl}$ were considered to have diabetes mellitus. Individuals with two-hour capillary glycemia $\geq 140 \mathrm{mg} / \mathrm{dl}$ and $<200 \mathrm{mg} / \mathrm{dl}$ were considered to have impaired glucose tolerance (IGT) and those with FCG $<140 \mathrm{mg} / \mathrm{dl}$ were considered to have normal glucose tolerance. Individuals with systolic $\mathrm{BP}(\mathrm{SBP}) \geq 140 \mathrm{mmHg}$ and diastolic $\mathrm{BP}(\mathrm{DBP}) \geq 90$ $\mathrm{mmHg}$ or taking an antihypertensive medication were considered to be hypertensive according to $\mathrm{WHO} / \mathrm{ASH}$ (2003). BMI between 18.5 to 24.9 was considered normal, 25 to 29.9 overweight and equal or higher than 30 obese.

Data was analyzed using the SAS statistical software. The difference between men and women was calculated by the Fischer test. The results are shown as mean and standard deviation or as percentage. The level of significance was set at $5 \%$.

\section{Results}

A total of 1716 people living in 245 selected residential address were registered, but 1282 were not eligible for the study: 1205 of them (70.2\%) because they were aged $<30$ years, 21 (1.2\%) because they were aged $\geq 70$ years and $56(3.3 \%)$ due to pregnancy. Initially, 434 subjects were enrolled but 13 subjects (3.0\%) were not at home on the day of the interview, the only reason of lack of participation in the study. The response rate was $97 \%$, which indicates the active cooperation of the eligible participants. Thus, 421 subjects participated in the first phase of the study and $130(30.8 \%)$ in the second phase, $46(35.3 \%)$ of them as control (corresponding to the each sixty consecutive subject who screened negative).

According to education level, 230 individuals (54.6\%) were illiterate, 142 (33.8\%) had basic level education and $49(11.6 \%)$ had secondary level education (Figure 1). No one had university education. With exception of only one individual classified as mixed skin color, $99.8 \%$ of individuals were of black skin color. Previously diagnosed diabetes mellitus was only known by one subject (8.0\% of all affected subjects with diabetes) on oral antidiabetic drug therapy. The majority of the subjects

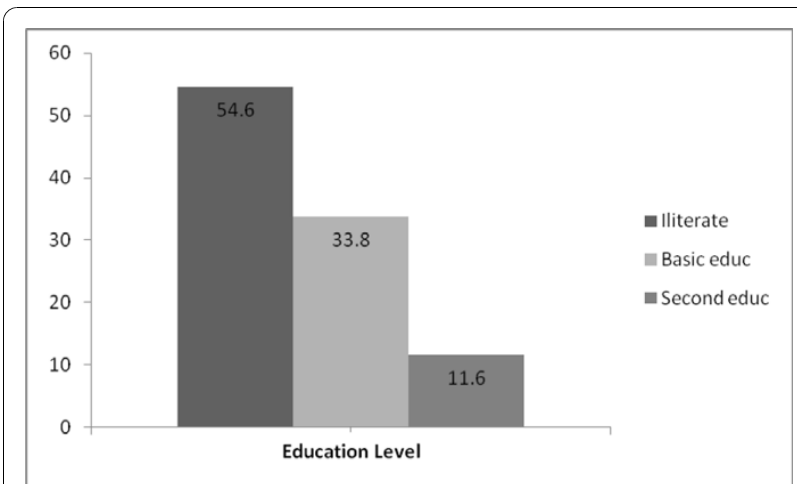

Figure 1 Educational status of individuals in the study sample 
Table 1 Prevalence of diabetes mellitus and impaired glucose tolerance in the study sample

\begin{tabular}{|c|c|c|c|c|c|c|c|c|c|}
\hline \multirow[t]{2}{*}{ Categories } & \multicolumn{3}{|c|}{ Total } & \multicolumn{3}{|c|}{ Women } & \multicolumn{3}{|c|}{ Men } \\
\hline & $\mathrm{N}$ & $\%$ & $\begin{array}{c}\mathrm{Cl} \\
(95 \%)\end{array}$ & $\mathrm{N}$ & $\%$ & $\begin{array}{c}\mathrm{Cl} \\
(95 \%)\end{array}$ & $\mathrm{N}$ & $\%$ & $\begin{array}{c}\mathrm{Cl} \\
(95 \%)\end{array}$ \\
\hline$\overline{D M}$ & 12 & 2.8 & $1.2-4.4$ & 8 & 2.7 & $1.2-4.2$ & 4 & 3.2 & $1.4-4.9$ \\
\hline IGT & 34 & 8.1 & $\begin{array}{l}5.5- \\
10.7\end{array}$ & 27 & 9.1 & $\begin{array}{l}5.2- \\
11.3\end{array}$ & 7 & 5.6 & $3.6-6.7$ \\
\hline $\begin{array}{l}\text { No DM-No } \\
\text { IGT }\end{array}$ & 375 & 89.1 & $\begin{array}{l}86.1- \\
92.2\end{array}$ & 262 & 88.2 & $\begin{array}{l}85.2- \\
91.6\end{array}$ & 113 & 91.2 & $\begin{array}{l}88.2- \\
94.6\end{array}$ \\
\hline
\end{tabular}

studied (70\%) were females and gender age group distributions were quite similar, ranging between $22 \%$ and $28 \%$.

Of the 421 subjects tested (30\% men and $70 \%$ women), 375 (89.1\%) were classified as individuals with normal glucose tolerance, $34(8.1 \%)$ as having impaired glucose tolerance, and $12(2.8 \%)$ were diagnosed with diabetes mellitus. Impaired fasting glycemia was verified in 51 individuals(12.1\%). The overall prevalence of diabetes mellitus in the study sample was $2.8 \%$ (95\% CI 1.2-4.4) and the overall prevalence of impaired glucose tolerance was $8.1 \%$ (95\% CI 5.5-10.7) (Table 1). Among 12 individuals who met the criteria for diabetes mellitus, $66.7 \%$ were females and $33.3 \%$ were males. Diabetes was diagnosed by the determination of fasting blood glucose in seven subjects (58\%) and by the $75 \mathrm{~g}$ oral glucose tolerance test in the remaining five subjects (42\%).

The prevalence of diabetes mellitus did not differ significantly between men $(3.2 \%, 95 \% \mathrm{CI} 1.4-4.9)$ and women $(2.7 \%, 95 \%$ CI $1.2-4.2)(p=0.47)$. On the other hand, the prevalence of impaired glucose tolerance among women showed almost twice that found in men ( $9.1 \%$ vs. $5.6 \%$, respectively, $\mathrm{p}=0.30)$. Of the 130 individuals submitted to the OGTT, five (4\%) screened positive for diabetes mellitus, 34 (26\%) screened positive for impaired glucose tolerance and 91 (70\%) were classified as having normal glucose tolerance. Of a total of 91 individuals whose 75 glucose tolerance tests were normals, $38(41.8 \%)$ showed previous fasting glycemia $<100 \mathrm{mg} / \mathrm{dl}, 47(51.6 \%)$ showed previous fasting glycemia $\geq 100$ and $<126 \mathrm{mg} / \mathrm{dl}$, and $6(6.6 \%)$ showed previous fasting glycemia $\geq 126$ and $<200 \mathrm{mg} / \mathrm{dl}$.

The mean age of individuals with diabetes mellitus was $54.3 \pm 10.7$ years (males: 53.5 years vs. females: 54.6 years) and the mean age of the study sample as a whole was $49.6 \pm 11.3$ years (males: 48.7 years vs. females: 49.9 years). Most of the individuals with diabetes mellitus were 50 to 69 years (58\%), whereas most of those without diabetes mellitus or impaired glucose tolerance were 30 to 49 years old (52\%). No difference was found in the age group distribution of individuals with impaired glucose tolerance. All the individuals diagnosed as having diabetes mellitus had an unknown family history.
Although the mean values of anthropometric data verified in the study sample were within the normal range, subjects with impaired glucose tolerance or diabetes mellitus had slightly higher values than those observed in the subjects without diabetes mellitus or impaired glucose tolerance (Figure 2). Overweight was present in $66.7 \%$ of the individuals with diabetes mellitus and $26.5 \%$ of individuals with impaired glucose tolerance showed overweight or obesity. Overweight or obesity was present in only $15.4 \%$ of the whole sample. Agricultural work was the most frequent occupation (76.7\% of participants).

Hypertension was found in $38.7 \%$ of the study sample as a whole $(37.6 \%$ among the subjects without DM or IGT) and in $47.8 \%$ of individuals with diabetes mellitus or impaired glucose tolerance.

\section{Discussion}

The prevalence of diabetes mellitus and impaired glucose tolerance in the province of Bengo was $2.8 \%$ and $8.1 \%$, respectively, which is similar to that found in subSaharan countries of Africa except South Africa, where higher prevalence were found. This was the first study of diabetes mellitus carried out in Angola, and therefore there are no previous data for comparison. The prevalence of diabetes mellitus found in this rural community of Angola allowed us to estimate a higher number of individuals with diabetes compared to that estimated by WHO, based on extrapolation of data from Central Africa countries like Cameroon whose rural prevalence of diabetes mellitus determined according to the same diagnostic criteria was $0.7 \%$ in 1996 [1].

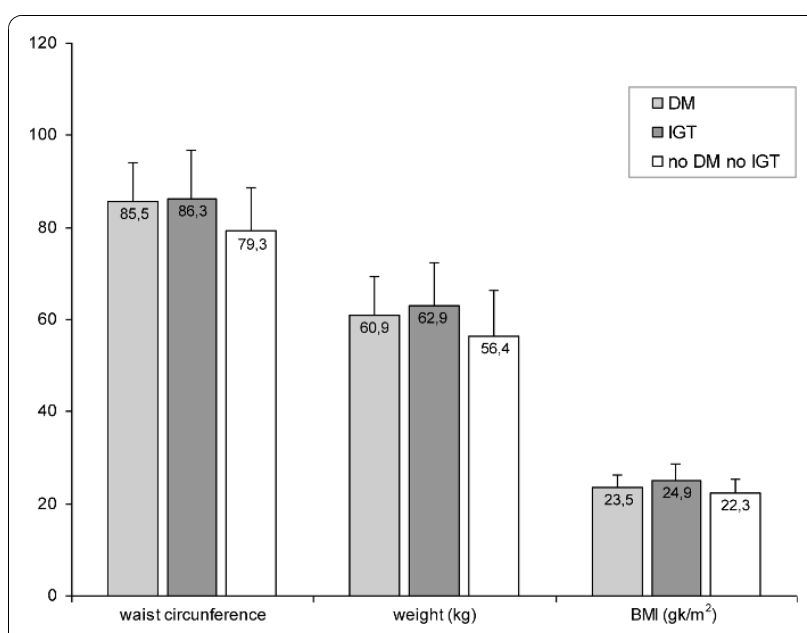

Figure 2 Anthropometric data (waist circumference, weight and BMI) of individuals with diabetes mellitus (DM) or impaired glucose tolerance (IGT) and without DM or IGT (noDM nolGT) 
As in other African rural communities, the prevalence of diabetes mellitus found in the present study was much lower than that found in African migrant communities, African Americans, Caribbean Africans in United Kingdom and Caucasians [3-5]. Complex carbohydrate consumption and high energy expenditure by agricultural workers lead not only to a low obesity prevalence but also to a low prevalence of diabetes. In addition, the low life expectancy in sub-Saharan African countries, except South Africa, contribute for this scenario $[10,12,13]$. In fact, Angola which life expectancy at birth of 39 years (men) and 41 years (women) [14,15], has a low number of people aged $\geq 40$ years, a situation reflected on age group distribution of individuals with diabetes mellitus and impaired glucose tolerance in the present study. The decreasing number of elderly people as a result of high mortality of people with diabetes mellitus due to lack of health care and to the HIV/AIDS epidemic may also contribute to this low prevalence of diabetes mellitus $[14,15]$.

Ninety-two percent of all cases of diabetes found were unknown before the survey. This rate is much higher than those reported in similar studies in other developing countries (the global average is around 50\%) [16] and may reflect less awareness to the disease and a lack of healthcare. Thus, there is a need for screening prevention programs on scientific and political agenda.

Some factors such as stress related to the long civil war, body loading with salt from consumption of products using a salt conservative method and psychological aspects could explain the high prevalence of hypertension in this community (38.7\%). Hypertension has been found to be high in African populations with and without diabetes $[7,17]$.

According to King and Rewers [18], the prevalence of diabetes mellitus in the rural community studied is low $(<3 \%)$ but the prevalence of impaired glucose tolerance is within the intermediate range (3-10\%), a fact that may imply a trend toward an increasing prevalence of diabetes in the future. The prevalence of overweight and obesity was also low. Hypertension appeared to be an important associated pathological situation not only in individuals with diabetes mellitus but also in those with impaired glucose tolerance.

\section{Conclusions}

Although the prevalence of diabetes mellitus was low, the prevalence of impaired glucose tolerance is considered to be within an intermediary range, suggesting a future increase in the frequency of diabetes in this population.

\section{Acknowledgements}

We thank the population and authorities of Caxito municipality for their cooperation. This research was funded by grants from Agostinho Neto
School of Medicine - Angola/Africa and Research Foundation of the University Hospital - School of Medicine of Ribeirào Preto-USP, Brazil.

\section{Authors' contributions}

ADEN, MCFF and MCF participated in the design of the study. ADEN and MCFF performed the data collection and the statistical analysis. ADEN, MCFF and MCF wrote the paper. All authors read and approved the final manuscript.

\section{Competing interests}

The authors declare that they have no competing interests.

Received: 16 July 2010 Accepted: 1 November 2010

Published: 1 November 2010

\section{References}

1. Mbanya JCN, Ngogang J, Salah JN, Balkau B: Prevalence of NIDDM and impaired glucose tolerance in a rural and an urban population in Cameroon. Diabetologia 1997, 40:824-829.

2. Sobngwi E, Mauvais-Jarvis F, Vexiau P, Mbanya JC, Gautier JF: Diabetes in Africans: epidemiology and clinical specificities. Diabetes Metab 2001, 27:628-634.

3. Mbanya JCN, Cruickshank JK, Forrestier T, Balkau B, Ngogang JY, Riste L, Forhan A, Anderson NM, Bennett F, Wilks R: Standardized Comparison of Glucose Intolerance in West African-Origin Populations of Rural and Urban Cameroon, Jamaica, and Caribbean Migrants to Britain. Diabetes Care 1999, 22:434-440.

4. Tull ES, Roseman JM: Diabetes in African Americans. In Diabetes in America. 2 edition. Edited by: Harris MI, Cowie CC, Stern MP, Boyko EJ, Reiber GE, Bennett PH. Washington, DC, U.S.Govt. Printing Office; 1995:613-630, (NIH publ. no. 95-1468).

5. Cowie CC, Harris MI, Silverman RE, Johnson EW, Rust KF: Effect of Multiple Risk Factors on Differences Between Blacks and Whites in the prevalence of Non-Insulin Diabetes Mellitus in the United States. American Journal of Epidemiology 1993, 37:719-732.

6. Dodu SRA: The Incidence of Diabetes Mellitus in Accra (Ghana): a Study of 4000 Patients. West African J Med 1958, 7:129-134.

7. Sobngwi E, Mbanya JC, Unwin NC, Porcher R, Kengne AP, Fezeu L, Minkoulou EM, Tournoux C, Gautier JF, Aspray TJ, Alberti KGMM: Exposure over the Life Course to an Urban Environment and its Relation with Obesity, Diabetes, and Hypertension in Rural and Urban Cameroon. International Journal of Epidemiology 2004, 33:769-776.

8. Ahrén B, Corrigan B: Prevalence of diabetes mellitus in North-Western Tanzania. Diabetologia 1984, 26:333-336.

9. Wild S, Roglic G, Green A, Sicree R, King H: Global prevalence of diabetes: estimates for the year 2000 and projections for 2030. Diabetes Care 2004 27:1047-1052.

10. Ceesay MM, Morgan MW, Kamanda MO, Willoughby VR, Lisk DR: Prevalence of diabetes in rural and urban populations in southern Sierra Leone: a preliminary survey. Tropical Medicine and International Health 1997, 2:272-277.

11. Torquato MTCG, Montenegro RMM Jr, Viana LAL, Souza RAHG, Lanna CMM, Lucas JCB, Bidurin C, Foss MC: Prevalence of diabetes mellitus and impaired glucose tolerance in the urban population aged 30-69 years in Ribeirào Preto(Sào Paulo), Brazil. Sào Paulo Medical Journal 2003, 12:224-230.

12. Swai $A B$, Lutale J, McLarty DG: Diabetes in Tropical Africa: a Prospective Study, 1981-7. I. Characteristics of Newly Presenting Patients in Dar as Salaan, Tanzania 1981-7. British Medical Journal 1990, 300:1103-1106.

13. McLarty DG, Kinabo L, Swai AB: Diabetes in Tropical Africa: a Prospective Study, 1981-7. Il. Course and Prognosis. British Medical Journal 1990, 300:1107-1110.

14. Instituto Nacional de Estatística de Angola. Relatório final do inquérito de indicadores múltiplos. Luanda 1998.

15. World Health Organization: WHO statistical information system. Angola core health indicators [http://www3.who.int/whosis/core/ core_select_process.cfm?country=ago\&indicators=select].

16. King H, Keuky L, Seng S, Klun T, Roglic G, Pinget M: Diabetes and associated disorders in Cambodia: two epidemiological surveys. Lancet 2005, 1633-1639. 
17. Cruickshank JK, Mbanya JC, Wilks R, Balkau B, McFarlane-Anderson N, Forrester T: Sick genes, sick individuals or sick populations with chronic disease? The emergence of diabetes and high blood pressure in Africanorigin populations. International Journal of Epidemiology 2001, 30:111-117.

18. King $\mathrm{H}$, Rewers M: Global estimates for prevalence of diabetes mellitus and impaired glucose tolerance in adults. Diabetes Care 1993, 16:157-177.

doi:10.1186/1758-5996-2-63

Cite this article as: Evaristo-Neto et al.: Prevalence of diabetes mellitus and impaired glucose tolerance in a rural community of Angola.

Diabetology \& Metabolic Syndrome 2010 2:63.

Submit your next manuscript to BioMed Central and take full advantage of:

- Convenient online submission

- Thorough peer review

- No space constraints or color figure charges

- Immediate publication on acceptance

- Inclusion in PubMed, CAS, Scopus and Google Scholar

- Research which is freely available for redistribution

Submit your manuscript at www.biomedcentral.com/submit
C Biomed Central 